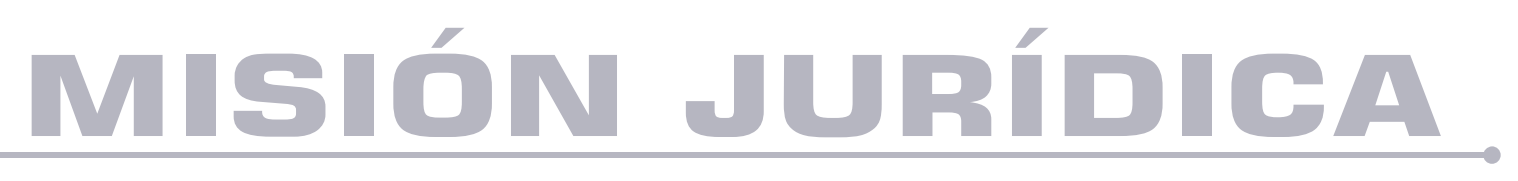

\title{
Análisis de la expresión motivos razonablemente fundados en el ámbito de la captura y ordenes de allanamiento y registro
}

Analysis of the expression "Reasonable Grounds" in the context of, Arrest and Search and Seizure warrants

Autor: Vladimir Rodríguez Sanabria

DOl: https://doi.org/10.25058/1794600X.1959

\footnotetext{
SP MISIÓN JURÍDICA A 


\title{
Análisis de la expresión motivos razonablemente fundados en el ámbito de la captura y ordenes de allanamiento y registro*
}

\author{
Analysis of the expression "Reasonable Grounds" in the context \\ of, Arrest and Search and Seizure warrants
}

\author{
Análise da expressão motivos razoavelmente bem \\ fundamentados em matéria de mandados de prisão e busca
}

\author{
Vladimir Rodríguez Sanabria ${ }^{a}$ \\ rodriguez_vladimir@hotmail.com \\ Fecha de recepción: 18 de agosto de 2020 \\ Fecha de revisión: 14 de septiembre de 2020 \\ Fecha de aceptación: 13 de diciembre de 2020
}

\section{DOI: https://doi.org/10.25058/1794600X.1959}

Para citar este artículo:

Rodríguez Sanabria, V. (2021). Análisis de la expresión motivos razonablemente fundados en el ámbito de la captura y ordenes de allanamiento y registro. Revista Misión Jurídica, 14(21), 241 - 253.

\section{RESUMEN}

Este artículo analiza la expresión "motivos razonablemente fundados" en el ámbito de la orden de captura y de los registros y allanamientos. Al efecto, realiza una búsqueda de criterios que la traten, tanto en la legislación y en la jurisprudencia nacionales como en la normatividad externa. Así, este trabajo se esfuerza por hallar unas reglas de decisión que fundamenten el sentido de la expresión en comento. Por ello, cuestiona la subjetividad que puede presentarse cuando al juzgador le corresponde expedir la correspondiente orden, sin el profundo análisis y justificación que se requiere para sostener una resolución judicial basada en "motivos razonablemente fundados". Finalmente, debate el influjo de las creencias y señala la duda y el conocimiento objetivo como base para entender la racionalidad de esta expresión.

\section{PALABRAS CLAVE}

Motivos razonablemente fundados; Subjetivismo; Órdenes judiciales; Conocimiento objetivo.

\footnotetext{
*Artículo original de reflexión.

a. El autor del artículo ha sido profesor en la Universidad Católica de Colombia y Cooperativa de Colombia, actualmente Conjuez de la Sala Disciplinaria del Consejo Seccional de Cundinamarca, ha sido asesor de asuntos disciplinarios y asesor jurídico en alcaldías municipales. Autor del libro Estudios del Honor como objeto de protección penal, así como artículos de derecho en la Universidad Católica de Colombia, Revista Latinoamericana de Derecho Penal y Criminología y de la Universidad Colegio Mayor de Cundinamarca. Con Estudios de Doctorado en la Universidad de Salamanca. Especializado en Gestión y Desarrollo Municipal y Departamental. Maestría en Filosofía del Derecho y Teoría Jurídica de la Universidad Libre.
} 


\section{ABSTRACT}

This article analyzes the expression reasons reasonably founded in the area of the arrest warrant and the searches and searches. To this end, it carries out a search for criteria that inform this question, both in national legislation and jurisprudence and in external regulations. Thus, this work strives to find decision rules that support the meaning of the expression in question. For this reason, it questions the subjectivity that may arise when the judge is responsible for issuing the corresponding order, without the in-depth analysis and justification required to uphold a judicial resolution based on reasonably well-founded reasons. Finally, it questions the influence of beliefs and points to doubt and objective knowledge as the basis for understanding the rationality of this expression.

\section{KEY WORDS}

Reasonably founded motives; Subjectivism; Warrant-Objective knowledge.

\section{RESUMO}

Este artigo analisa a expressão "motivos razoavelmente fundamentados" na área do mandado de prisão e buscas. Para tanto, procura os critérios que a abordam, tanto na legislação e jurisprudência nacionais quanto nas regulamentações externas. Assim, este trabalho busca encontrar regras de decisão que sustentem o sentido da expressão em questão. Portanto, questiona a subjetividade que pode surgir quando o juiz é responsável pela emissão da ordem correspondente, sem a análise aprofundada e as justificativas necessárias para sustentar uma resolução judicial com base em "razões razoavelmente fundamentadas". Por fim, discute a influência das crenças e aponta a dúvida e o conhecimento objetivo como base para a compreensão da racionalidade dessa expressão.

\section{PALAVRAS-CHAVE}

Razões razoavelmente bem fundamentadas; subjetivismo; ordens judiciais; conhecimento objetivo.

"Aprender a dudar es aprender a pensar" Octavio Paz

\section{INTRODUCCIÓN}

La expedición de orden de captura u orden de registro y allanamiento se basa en la existencia de "motivos razonablemente fundados", cuyo respaldo reside en declaraciones juramentadas de testigos o informantes, $\mathrm{o}$ en elementos probatorios o, evidencia física que vinculen el bien por registrar con el delito investigado, según lo dispuesto en el artículo 221 del Código de Procedimiento Penal Colombiano. A esta misma caracterización de los motivos razonablemente fundados, responde la aplicación de la orden de captura conforme a lo dispuesto en el artículo 297 del mismo ordenamiento. Y si bien, desde el punto de vista de los derechos fundamentales podría predicarse que existe diferencia entre el allanamiento y la captura en cuanto afectan derechos de un contenido distinto, es decir, en el primero se afecta la propiedad o la intimidad, mientras que en el segundo se afecta la libertad, lo cierto es que la expresión "motivos razonablemente fundados" continua siendo imprecisa, lo que afecta invariablemente las diligencias que dependen de esta expresión, como ocurre, precisamente en los eventos de captura, de allanamiento y registro. Este carácter de imprecisión ha sido denunciado en doctrina reciente, que a su vez reclama por desarrollar una sistemática procesal, en orden a concretar el contenido de los motivos fundados (Zuluaga E., 2014).

Lo anterior, obedece a que los criterios del significado de esta expresión no están regulados $\mathrm{y}$, también principalmente, porque se trata, en realidad, de un problema de conocimiento, es decir, de cómo el juez racionaliza y da credibilidad a los elementos aportados por la fiscalía para decidirse a expedir las respectivas ordenes de captura o de registro y allanamiento.

Surge entonces, el siguiente interrogante, $i$ en dónde se puede hallar un fundamento objetivo que ofrezca significado a la expresión "motivos razonablemente fundados"? Esta cuestión se torna relevante, por cuanto de dicha expresión, depende la realización y justificación de una diligencia, bien sea, de captura o de allanamiento y registro.

En estos términos, el presente escrito tiene como finalidad determinar que el sentido de aquello que se considere como motivos razonablemente fundados pertenece al ámbito 
del conocimiento humano y allí es donde está su punto de partida y es el campo en donde debe dilucidarse. No supone, desde luego, ignorar la esfera jurídico-penal. Muy al contrario, se trata de señalar que, desde el análisis de la actividad de conocer, puede hallarse la manera para entender esta expresión.

Para tal fin, se abordará en primer lugar, la situación a nivel normativo y jurisprudencial, en donde, precisamente, se evidencia que hay un desarrollo significativo para la expresión objeto de análisis; $y$, a su vez, se incluye como valioso referente un ejemplo traído de la normatividad externa, que podría ser referente para el caso colombiano. Luego, se hará un breve examen del tema en los niveles de la razonabilidad de los motivos fundados, en el tema del conocimiento y de la manera en que la duda y las creencias juegan un papel importante en la toma de decisiones. Finalmente, a modo inacabado de conclusión, se plantea la propuesta de enfatizar en la práctica del conocimiento objetivo como insumo que permite realizar el control material de los elementos y de la orden judicial para los eventos de captura y de allanamiento y registro y, con ello, sortear las inveteradas dificultades que ha traído consigo, el subjetivismo o decisionismo judicial, más aún, en estos casos que afectan derechos fundamentales como la libertad o la inviolabilidad del domicilio.

\section{HERRAMIENTAS JURÍDICAS PARA DECIDIR}

\subsection{Los motivos razonablemente fundados en la legislación colombiana}

Se comienza por examinar las herramientas que el legislador le ha proporcionado al juez para que, desde los motivos razonablemente fundados, proceda a limitar los derechos fundamentales. Entre las referencias que la legislación procedimental penal colombiana, trae al respecto, están: el artículo 220 de la Ley 906 de 2004, que señala:

“Artículo 220. Fundamento para la orden de registro y allanamiento. Sólo podrá expedirse una orden de registro y allanamiento cuando existan motivos razonablemente fundados, de acuerdo con los medios cognoscitivos previstos en este código, para concluir que la ocurrencia del delito investigado tiene como probable autor o partícipe al propietario, al simple tenedor del bien por registrar, al que transitoriamente se encontrare en él; o que en su interior se hallan los instrumentos con los que se ha cometido la infracción, o los objetos producto del ilícito" (negrillas nuestras).

En esta norma se le indica al juez que la existencia de "motivos razonablemente fundados" para expedir una orden de allanamiento y registro, depende de los medios cognoscitivos previstos en el código y que, además, esos motivos le permiten concluir varias situaciones en relación con el delito, así, por ejemplo, que el propietario, el tenedor o quien se encuentre en el bien es autor o participe del delito o que en el bien objeto de registro se hallan objetos productos del ilícito.

En este sentido, el motivo razonablemente fundado versa sobre la existencia de autoría o participación en el delito o, acerca de la presencia de objetos que sean producto de este. Aquí inicia el camino del conocimiento del juez, cuya primera pieza será, entonces, la existencia de un delito que también se está investigando. Esta situación, a primera vista, debería generar dudas para el juez, puesto que el hecho central de la investigación, que es el delito, también está en averiguación. Por tanto, no podría decirse que existe una hipótesis concreta que le permita ordenar una captura. Sin embargo, la falencia, es superada mediante los informes de policía judicial, declaración de testigo o informante, elementos probatorios y evidencia física, pues así parece sugerirlo el artículo 221 de la misma ley:

Artículo 221. Respaldo probatorio para los motivos fundados. Los motivos fundados de que trata el artículo anterior deberán ser respaldados, al menos, en informe de policía judicial, declaración jurada de testigo o informante, o en elementos materiales probatorios y evidencia física que establezcan con verosimilitud la vinculación del bien por registrar con el delito investigado.

Cuando se trate de declaración jurada de testigo, el fiscal deberá estar presente con miras a un eventual interrogatorio que le permita apreciar mejor su credibilidad. Si se trata de un informante, la policía judicial deberá precisar al fiscal su identificación y explicar por qué razón le resulta confiable. De todas maneras, los datos del informante serán 
reservados, inclusive para los efectos de la audiencia ante el juez de control de garantías.

Cuando los motivos fundados surjan de la presencia de elementos materiales probatorios, tales como evidencia física, vídeos o fotografías fruto de seguimientos pasivos, el fiscal, además de verificar la cadena de custodia, deberá exigir el diligenciamiento de un oficio proforma en donde bajo juramento el funcionario de la policía judicial certifique que ha corroborado la corrección de los procedimientos de recolección, embalaje y conservación de dichos elementos.

Es decir, los motivos razonablemente fundados requieren de un correspondiente respaldo probatorio, tal y como se advierte en la citada ley. También queda suprimida la posibilidad de la defensa o del mismo capturado para contradecir en audiencia ante el juez de garantías el elemento probatorio que sostiene la orden de captura, como sería, por ejemplo, el derecho de contrainterrogar al informante o testigo.

Ahora, cómo funcionan las cosas para fundamentar una orden de captura. Al efecto, el artículo 297 de la Ley 906 de 2004, modificado por el artículo 19 de la Ley 1142 de 2007 indica:

Artículo 297. Requisitos generales. Para la captura se requerirá orden escrita proferida por un juez de control de garantías con las formalidades legales $y$ por motivos razonablemente fundados, de acuerdo con el artículo 221, para inferir que aquel contra quien se pide librarla es autor o partícipe del delito que se investiga, según petición hecha por el respectivo fiscal

Igual que en el caso de los allanamientos, se requiere del respaldo probatorio que sustente los motivos fundados para inferir la comisión o participación en un delito. En este orden de ideas se concluye que los motivos fundados no operan por sí mismos, sino que requieren de un respaldo probatorio. Sin embargo, de la normatividad señalada no se concluye cual es el contenido de esta expresión legal. Pero, por otra parte, el aspecto de ser "razonables" dota de garantía las diligencias que se hagan, bien sea allanamiento o captura. Quiere decir, al operador judicial no le es exigido un análisis exhaustivo cuando ordena una captura, en cuanto no existe un baremo o requisitos que configuren un motivo razonablemente fundado. Pues, no estamos hablando de una categoría jurídica, sino que es, de hecho, una consideración que hace el juez de garantías, desde su raciocinio, acerca del informe de policía judicial, de una declaración jurada o acerca de la versión del testigo.

Al ser así, también es claro, entonces, que de la normatividad no se puede extraer el contenido de aquello que se entienda como un "motivo razonablemente fundado" y que por ahora el único dato que se tiene es el análisis subjetivo que hace el juez para señalar que existe alguna circunstancia que justifique una orden de captura o un allanamiento.

\subsection{Los motivos razonablemente fundados en la jurisprudencia}

En el ámbito de la jurisprudencia, tenemos por ejemplo, la Sentencia C-673 (2005) emanada por la Corte Constitucional, en la que se precisan los elementos que soportan dichos motivos. La referida sentencia, informa que la declaración jurada de testigo o informante solo atañe como soporte de la imposición de una medida restrictiva de la libertad y que, además, no se entiende para efectos de valoración de la responsabilidad penal del imputado. En mejores palabras, se pronuncia sobre los requisitos y condiciones de estos elementos probatorios, pero no aclara el concepto de "motivos razonablemente fundados".

Ahora bien, existe un aparte de esta misma sentencia que podría indicar, la raíz o el origen de un motivo fundado, es decir, el respaldo que deberá tener en cuenta el juez para sustentar materialmente los motivos fundados, a saber:

Pues bien, los motivos fundados para ordenar un registro y allanamiento, deben encontrarse respaldados, al menos, en informe de policía judicial, declaración jurada de testigo o informante, $o$ en elementos materiales probatorios y evidencia física que establezcan con verosimilitud la vinculación del bien por registrar con el delito investigado. Es decir, la expedición de una orden de registro y allanamiento no queda al arbitrio del fiscal que la ordena, sino que deberá tener un soporte o respaldo al menos en un informe, declaración jurada o elementos materiales probatorios y evidencia física, como 
garantía de la viabilidad de la diligencia, en los términos determinados por la norma acusada a fin de que el juez pueda acceder a una información que le permita realizar un efectivo control de legalidad.

De la anterior manera, se establece la necesidad de un soporte probatorio para los motivos fundados y, de este mismo soporte se desprende la verosimilitud, en este caso, del vínculo entre el bien por registrar y el delito investigado. Puede pensarse, entonces que la verosimilitud aproxima o da una idea para configurar la presencia de motivos razonablemente fundados. No obstante, la sentencia citada, anuncia que, en el mismo soporte probatorio, está el motivo fundado o por lo menos que en el examen de la declaración del testigo o informante radica el motivo fundado, es decir:

Así las cosas, la declaración jurada de testigo o informante sirve de respaldo al fiscal para considerar que existen motivos fundados para decretar una orden de allanamiento y registro, encaminada a la obtención de materiales probatorios y evidencia física o la captura del indiciado, imputado o condenado, pero ésta no puede ser considerada como declaración de un testigo de cargo.

Según esto, la formalidad del juramento dota de confiabilidad la declaración rendida por el testigo o informante. Por ende, la discusión en torno al grado de lo verosímil o de lo confiable como base de los motivos razonablemente fundados no se plantea como algo necesario y, en cualquier caso, se deja al arbitrio del juez aquello que considere fiable o verosímil. Esta situación conlleva al antiguo problema de lo razonable de las decisiones judiciales. Desde esta primera entrada a la jurisprudencia constitucional, se observa que el criterio que soporta un motivo razonablemente fundado para avalar una orden de captura, seguirá siendo el criterio del juez. De hecho, esta es la constante, pues los restantes pronunciamientos al respecto, no han tocado concretamente los motivos razonablemente fundados. En tal sentido, la Sentencia C-185 (Corte Constitucional, 2008) resolvió en torno a la captura excepcional por parte de la Fiscalía, declarando la exequibilidad de los artículos demandados, entre ellos el artículo 221 de la Ley 906 de 2004, situación que otra sentencia del mismo año, la Sentencia C-226 (Corte Constitucional, 2008), no varió en absoluto.
De este modo, es posible afirmar que desde la ley y la jurisprudencia, al juez de garantías se le proporcionan las herramientas para soportar su decisión, cuando considera que existen motivos razonablemente fundados para proferir orden de captura o de allanamiento, valga decir, declaración de informante, testigo o algún elemento probatorio que lo lleve a tal decisión, pero, no informa acerca de los criterios a tener en cuenta. En concreto, del contenido de lo que se pueda apreciar como "motivos razonablemente fundados", pues, en todo caso, queda a merced del juez, no habiendo, entonces, como al principio se decía, un concepto sistemático de tal expresión.

\subsection{Un ejemplo de reglas de decisión para los motivos fundados: la legislación procesal de Puerto Rico}

La decisión del juez para el caso de la captura no está sujeta a reglas claras, como lo sería en comparación con la regla tenida en cuenta para decidir el proceso de fondo, pues continúa siendo un ejercicio de operación mental, dependiente de unas pautas diferentes a las constitucionales $y$, por supuesto, de las ordinarias legales. Pensando en un escenario normal, el despacho del fiscal solicita al juez de garantías orden de captura basado en información que, no siendo prueba de cargo, no implicaría la exigencia de la legalidad de la información obtenida. En este sentido, es una decisión sin reglas que, visto así, estaría contraviniendo la característica de actividad reglada, la cual se constituye como uno de los pilares de los Estados democráticos. ¿Puede decirse entonces que quizá faltan reglas para saber cuándo estamos frente a los "motivos razonablemente fundados"? Veamos cómo opera, por ejemplo, en otras latitudes, el fundamento para decidirse a ejecutar un procedimiento de captura. Para tales efectos, puede verse la forma de fundamentar un arresto en el Procedimiento Criminal del Estado Libre Asociado de Puerto Rico, cuya Regla 6 indica lo siguiente:

\section{Regla 6. ORDEN DE ARRESTO A BASE DE UNA DENUNCIA. (34 L.P.R.A. Ap. II R 6)}

(a) Expedición de la orden. Si de la denuncia jurada o de la declaración o declaraciones juradas sometidas con la denuncia o del examen bajo juramento del denunciante o sus testigos, si algunos, constare que hay causa probable para creer que se ha cometido el delito por la persona o personas contra 
quienes se imputa, el magistrado expedirá la orden para el arresto de dichas personas, con excepción de lo dispuesto en la Regla 7(a). La determinación de causa probable podrá estar fundada total o parcialmente en una declaración por información o creencia con suficiente garantía circunstancial de confiabilidad...

En esta determinación de causa probable el imputado tendrá derecho a estar asistido de abogado, a contrainterrogar a los testigos en su contra y a ofrecer prueba en su favor... (Código de Procedimiento penal de Puerto Rico, 1963).

Del anterior texto legal, se concluye que las reglas para decidir sobre una captura, en este caso, arresto, son más exhaustivas, más exigentes $\mathrm{y}$, con la importante posibilidad de controvertir al testigo, lo cual es una garantía, que en el caso del ordenamiento colombiano no está contenida para los eventos de captura y allanamiento. Por su parte, los conceptos de "causa probable" o de "razonable certeza", aparecen en este como fundamento para guiar la decisión del magistrado, por tanto, nuevamente se está frente al problema de los criterios que conforman los citados conceptos. Es decir, se llega a la misma problemática de la noción de motivos razonablemente fundados.

Sin embargo, se rescata de este ordenamiento, la posibilidad de la contradicción respecto de la denuncia o de la testimonial. Esta actuación brinda mayores herramientas de decisión al juez, incidiendo de manera positiva en la promoción y vigencia del derecho de la libertad en el caso de una orden de arresto. La posibilidad de controvertir llevará a una decisión más objetiva y menos permeada por la subjetividad. La causa probable que el magistrado tenga para tomar la respectiva decisión, será indudablemente, más respetuosa con los derechos del ciudadano, toda vez que si bien la emisión del arresto está en cabeza del magistrado, también es cierto que en la hechura de la decisión interviene la persona destinataria de la orden, utilizando su derecho de defensa y de contradicción, lo cual disminuye el índice de error o de arbitrariedad, además que la decisión que se tome gana en garantías en cuanto al ciudadano se le permite contradecir aquellos medios probatorios que el magistrado tendrá en cuenta en la correspondiente decisión (Borrero \& Sampedro, 2010).
Lo anteriormente expuesto conlleva a sostener que una decisión que involucre más reglas y limites resulta ser garantista y respetuosa de los derechos humanos. Así las cosas, el problema de los "motivos razonablemente fundados" pasa por la posibilidad de controvertir el material que soporta la razón para arrestarlo. Sin embargo, en la legislación de Colombia, ello no ocurre y quizá podría tenerse en cuenta en un futuro para una reforma en la legislación.

¿Mientras tanto, qué ocurre? ¿En dónde se podrá hallar una garantía de racionalidad sobre la cual argumentar los motivos fundados para decretar una orden de captura? Se vio, en el ejemplo propuesto, que esta racionalidad la construyen por medio del debate probatorio, salvo, incluso, los problemas de conocimiento del juez, en cuanto las partes conocen y participan del material probatorio arrimado para construir la respectiva orden de arresto. También se sabe que en la legislación colombiana no sucede de esta manera y ello profundiza el problema, pues al no existir reglas de decisión, entonces la correspondiente resolución judicial queda sujeta a la subjetividad del juez y, por esto mismo, a sus creencias y prejuicios, -situación común a todos los seres humanos-, y que, desde luego, influye en la razonabilidad de la decisión.

\section{DEL ANÁLISIS DE RAZONABILIDAD EN LOS MOTIVOS FUNDADOS}

Entonces, el problema de definir la razonabilidad de los motivos fundados en la expedición de una orden de captura no lo ha resuelto la ley, tampoco la jurisprudencia o quizá sí, trasladándole este problema al juez. En este orden de ideas, el ámbito para resolver el problema acerca del fundamento de los "motivos razonablemente fundados" opera en la manera como el juez decida tal cuestión.

Así, por ejemplo, la expedición de una orden de captura como producto de una solicitud del fiscal, implica la decisión acerca de la restricción al derecho fundamental de la libertad. Sin embargo, no se aplican las reglas probatorias para fundamentar dicha decisión, pues como se vio, basta la existencia de una declaración jurada de testigo o informante. ¿Si ello es así, entonces al juez de garantías en la audiencia de legalización de captura no le es exigible ningún esfuerzo argumentativo? ¿Será suficiente, pues, con la 
presentación de la solicitud hecha por el fiscal? ¡Cuál es, entonces, el control de legalidad que se hace en dicha audiencia? Podrían surgir más cuestionamientos e interrogantes, aunque al final de todo, se da la urgente necesidad de exigir unos requisitos argumentativos al juez de garantías, cuando se ejerce el control de legalidad de la captura en la respectiva audiencia, es decir, que el juez explique y sustente porqué existen motivos razonablemente fundados que no pueden ser confundidos con la presencia de algún elemento probatorio. No basta el solo ejercicio de mención, es lógicamente admisible exigir que se presente el material de conocimiento correspondiente o relacionado con el delito que se investiga.

El juez debe establecer el objeto sobre el cual hará su pronunciamiento, en este caso, la procedencia de una orden de captura. Al efecto, la situación es la ocurrencia de un delito y los "motivos razonablemente fundados" se tienen para establecer la participación del autor bien sea en orden al registro y allanamiento o en la captura en el caso del artículo 297 de la Ley 906 de 2004. Si ello es así, la primera condición a establecer es el delito en sí, es decir, que exista evidencia y luego si procede estudiar la evidencia de los autores o participes. No sería suficiente argumentar, entonces, una autoría con un acta de inspección a cadáver, pues dicho documento no es idóneo o válido para establecer autoría en cuanto señala la causa de la muerte, pero no necesariamente indica quien fue el causante de esta; y así, se podrían mencionar otras situaciones. Se requiere de la existencia de elementos más contundentes en orden a establecer los motivos razonablemente fundados. Esto último, en concordancia con la misma normatividad que indica como fuentes de información, para soportar dichos motivos, las declaraciones juradas de informantes $o$ testigos, así como otros elementos materiales probatorios, frente a los cuales la Sentencia C 673 de 2005 enseña que deben ofrecer confiabilidad y verosimilitud.

Con todo, el tema de la razonabilidad no se ha resuelto. Pues no existen criterios concretos de los "motivos razonablemente fundados" y continúa siendo un espectro bastante amplio de decisión. Deberían estar regulados o, por lo menos, crear unas reglas para decidir. No se trata desde luego, de restringir al extremo el oficio del juez en el decreto de una orden de captura o de allanamiento. Lo que se pretende es ajustar la decisión judicial a unos criterios que se correspondan con la limitante que imponen las garantías fundamentales, que pueden verse desbordadas en cuanto no exista, precisamente, una serie de reglas para decidir, sobre todo en un tema tan delicado como la restricción de la libertad (Feteris, 2007, p. 283).

\section{LA DUDA VS LAS CREENCIAS EN LA DECISIÓN JUDICIAL}

Toda decisión judicial no puede, ni debería sustraerse de una depurada racionalidad, pues sobre esta última radica la vigencia de las libertades y garantías fundamentales (Alexy, 1998, p. 21). Por consiguiente, el control material en la audiencia de legalización de captura surge como actividad relevante, pues permite examinar los aspectos sustanciales de la diligencia de captura y con ello, la decisión que se produzca será más racional en cuanto se ha abordado no solo la formalidad, sino también la materialidad del soporte material que origina la diligencia, por ejemplo, la fiabilidad del testigo o el control de la evidencia física, entre otros.

A pesar de ello, la normatividad y la jurisprudencia insisten en que únicamente es admisible el control de la formalidad en la audiencia de legalización de captura (Sentencia C-366, 2014), MP. Nilson Pinilla Pinilla, ajustado a los requisitos constitucionales y legales. Con esto, resulta claro que el examen de los motivos razonablemente fundados depende del juez. Si esto es así, la racionalidad de la decisión del juez, no está en la norma o en la cita jurisprudencial, ello son herramientas para decidir y que efectivamente ayudan a encontrar una decisión adecuada y racional al evento de captura presentado, pues, la racionalidad está en el mismo ser humano que profiere la decisión, es decir, la persona denominada como juez de garantías.

En efecto, el juez, como todos los seres humanos, tiene como punto de partida, en su experiencia de adquisición y posterior producción de conocimiento, a la duda. A excepción, claro está, de los fanatismos de cualquier credo, clase o tendencia que nunca tienen duda de sus errores. Por tanto, el juez no puede soportarse en sus creencias para formar una decisión. Una decisión racional está libre de todo prejuicio. Ahora bien, si el juez no analiza conforme a sus creencias, ¿entonces qué debe hacer para construir su 
decisión? El camino para resolver esto, radica en admitir que la duda es el punto de partida para decidir.

La duda exige, al juez realizar un análisis concienzudo de la declaración del testigo o del informante, e incluso sugiere hacer un control material de los elementos puestos en su conocimiento. La duda garantiza la racionalidad y, por esto mismo, se constituye como garantía de los derechos fundamentales.

Cabe recordar que, en orden a imponer alguna sanción, el operador debe haber salido del estado de "duda razonable". De hecho, en todas las experiencias científicas o no, lo cual no excluye a la judicial, el ser humano siempre estará abocado a la duda. Por eso, causa sorpresa que se tomen decisiones judiciales de vulneración a libertades fundamentales pasando por alto lo falible y dubitativo de la inteligencia humana (Mill, 2004, p. 78).

Si la duda no es superada en el juicio, entonces el resultado será una sentencia absolutoria, pero ¿por qué razón no ocurre lo mismo con la legalización de la orden de captura? ¿No es contradictorio que un control formal de la orden de captura y la consecuente detención intra mural resulte después derrotado en un juicio con base en el control material que es realizado en el debate del proceso penal? ¿Si las garantías son el epitome de la racionalidad humana porque son vulneradas a través de control formal que hace el juez de garantías? Aceptar la duda del juez como punto de partida y salir de ella por medio de un control material puede constituirse en un medio de solución garantista.

Respecto de los "motivos razonablemente fundados", el juez debe superar lo dubitable de los elementos que van a soportar su decisión. Por ejemplo, el examen de la declaración jurada del testigo o informante, parecería ser suficiente para superar la duda del juez y, en consecuencia, decretar la captura. Así las cosas, la pretendida racionalidad se transforma en creencia, en mejores palabras, en un acto de fe en lo dicho por el informante o testigo. Con ello es evidente que la decisión se torna en irracional, aunque se ajuste a los cánones de la legalidad. Además de ser una cuestión que vulnera el sentido de justicia, también va en contravía de la mesura $\mathrm{y}$ racionalidad exigida al sistema judicial en sus decisiones. Por ello, es cada vez más urgente avanzar en el control material de la decisión que ordena la captura, sobre todo en su soporte, es decir, en la racionalidad de los motivos razonablemente fundados.

En consecuencia, si se pretende enderezar la apreciación acerca de los "motivos razonablemente fundados", apelando al sentido común o al uso de experiencias anteriores, tomando como base, las capturas realizadas por delitos similares o en situaciones parecidas, se está nuevamente, en el campo de la creencia; pues, un prolongado y determinado uso genera una creencia, la cual no puede ser obviada apelando a la formalidad. De hecho, puede ocurrir que el juez fundamente su decisión desde la legalidad pertinente y el inculpado al fin de cuentas no sabe cuál fue el fundamento material para ordenar la captura.

La propia opinión del operador no puede quedar oculta detrás del formulismo del procedimiento, pues ello conduce a que, aquella se convierta en el fundamento de la correspondiente decisión. Es sensato exigir algo más que el mero juramento del testigo o informante para decretar la orden de captura, pues, al fin y al cabo, es bueno recordar que la declaración puede ser falsa y que la "justicia premial" obligue a declarar sobre situaciones a todas luces inverosímiles o por lo menos erradas. Lo anterior debería pasar a ser objeto de análisis por parte del juez.

En este orden de ideas, se pueden ver los caminos para salir de la duda, sosteniendo desde ya que la solución no es, precisamente, la creencia o fe puesta en el declarante. Deben existir una serie de razones de tal suficiencia que por sí mismas permitan al juez salir tanto de la duda como de la creencia o si se quiere, de su propia opinión. Para ello, entonces, debe haber una evaluación objetiva de los elementos puestos en conocimiento del juez para fundar su decisión. Además, en todo caso, ha de admitirse que se está aún, en el terreno de lo hipotético, de lo conjetural. Las razones para tomar tal decisión no estriban en la legalidad, sino en la existencia de los motivos razonablemente fundados.

Ya se vio que la ley es presupuesto, pero no es el suficiente y que todavía se está en el terreno de la duda, pues el control formal no hace que la decisión sea racional. 
Del mismo modo, el sentido común de la humanidad está impregnado de las creencias y prejuicios. En este orden de ideas se puede observar cómo opera el sentido común en la decisión del juez. Así, ya recopilados los elementos materiales, el problema es cómo el juez ha de concluir sobre la razonabilidad de proferir una orden de captura.

En este punto, la decisión queda en manos del juez, pero, ¿cómo llega a decidir? Desde luego será basado en el sentido común, es decir, los términos de voz autorizada en temas del conocimiento y de la producción del conocimiento como la de Popper (2016, p. 17) quien así manifiesta en cuanto al sentido común, que:

La teoría del conocimiento del sentido común, que he apodado la teoría de la mente como un cubo queda perfectamente recogida en la frase nada hay en el intelecto que no haya pasado antes por los sentidos. A pesar de todo esperamos cosas y creemos con firmeza en ciertas regularidades ... La respuesta del sentido común consiste en decir que estas creencias surgen en virtud de reiteradas observaciones hechas en el pasado.

Lo anterior indica la manera como trabaja la mente humana y que se aplica, desde luego, en la labor del juez. Así pues, en la búsqueda de la explicación de los motivos razonablemente fundados en la orden de captura o de registro $\mathrm{y}$ allanamiento, se tiene que los jueces en sus deliberaciones parten o se fundamentan en el sentido común, o más exactamente en la creencia, en un oficio que se viene desarrollando por mucho tiempo y cuyas pautas vienen fijadas en patrones ya elaborados. Este es, entonces, el universo de criterios que informan la decisión del juez, es decir, este será el sentido común en el que se basa el juez para proferir la respectiva orden. A esto se añade un posible criterio que informa la voluntad de los jueces y es que el derecho penal, siendo un medio de control social, genera en el Estado y en buena parte de los ciudadanos, una necesidad de mantener cierto orden, por ello, los motivos razonablemente fundados participan o mejor aún, son consecuencia de esta idea.

\section{EL ANÁLISIS OBJETIVO DEL JUEZ}

Se observa que los jueces parten de un determinado universo de ideas cuando soportan una decisión. También, lo falible de esas creencias $\mathrm{y}$ que, en cualquier caso, el punto de partida será la duda. Si ello es así, ¿cómo justificar los motivos razonablemente fundados para una orden de captura? Serán pues las creencias y sus derivaciones.

Así, en primer lugar, se tiene la definición de "motivo fundado" que, a su vez, se supone está garantizada con el uso de "razonablemente fundado". En este sentido, la acepción "motivo" refiere a la razón o el fundamento para ejecutar alguna acción. Conforme a lo anterior, el motivo fundado seguirá configurándose en la mente del juez.

Entonces, ¿cuál será el análisis que debe hacerse para justificar y exponer los motivos razonablemente fundados? ¿Cómo deben ser argumentados? ¿Es suficiente señalar que existe declaración de testigo o informante? Además, en cuanto no existe posibilidad de contrainterrogar, tampoco se pueden presentar pruebas a favor en esta etapa de investigación, entonces, necesariamente el peso de la argumentación recae en el juez de garantías.

Ahora bien, dada la tendencia constitucional que inspira el procedimiento penal colombiano, se ha exigido que los jueces decidan también con base a lo ordenado en la constitución. Ello implica examinar la materia primaria que sería los elementos que le han sido aportados para proferir la orden de captura, luego ajustarla a la legalidad y que no vulnere el orden constitucional establecido. Desde luego, todo surge de los elementos sobre las cuales va a decidir, situación que denominada argumentación fáctica.

La argumentación fáctica es al fin de cuentas, la principal argumentación y de la cual, tanto la legal, como la constitucional, vienen a darle solidez a unos hechos verificados, al atenerse, por ejemplo, a la validez del testimonio. Siendo, de esta manera las cosas, se persiste en la crítica del conocimiento del juez, pues seguirá siendo un tema del sentido común que inunda el juicio del fallador en cuanto es una situación connatural a todo ser humano. Por esto, el análisis del conocimiento objetivo surge como importante en orden a mantener las garantías constitucionales en el momento de la decisión judicial. 
Por ello, el problema es de conocimiento, es saber cómo asume el juez los elementos puestos en su mente, cómo desprende de ellos juicios de valor, en este caso, el de ordenar una captura, cómo adopta dicha orden. Es un estudio que va más allá de los patrones legales y constitucionales. Y es importante, por cuanto de este análisis dependerá en últimas la legalidad y la constitucionalidad de la decisión tomada. En efecto, la norma señala que de los motivos razonablemente fundados se desprenda que la persona participó de alguna forma en el delito investigado para ordenar la respectiva detención. Empero, los elementos aportados para tomar tal decisión, no pasan por el filtro probatorio o por lo menos no se pueden presentar elementos a favor del inculpado. De hecho, el control sobre la captura es de índole formal y no ha hay posibilidad de, por ejemplo, contrainterrogar al testigo o informante. Por esta razón, es que la discusión sobre la racionalidad de "los motivos razonablemente fundados" es un tema de epistemología judicial, pues lo concerniente a la legalidad y constitucionalidad de la normativa sobre este aspecto, ya ha sido resuelto en sendos fallos de la Corte Constitucional como la SC-673de 2008 o la SC-366 de 2014.

Las decisiones judiciales, además de cumplir con los requisitos de legalidad y de constitucionalidad también deben estar exentas de toda creencia o fe del juez (Ferrer, 2007, p. 146). Esto nos lleva entonces a una calidad de conocimiento objetivo para asumir y decidir sin prejuicios, tendencias y, en las que la protección de las libertades y garantías prevalezca.

Bajo esta consideración, surge la pregunta acerca de lo pretendido con la orden de captura o de allanamiento, es decir, ¿el juez de garantías busca alguna verdad? La respuesta es negativa en tanto no es su función, luego la pregunta por los fines no es lógica en esta situación. Sin embargo, si el juez no debe resolver acerca de una hipótesis, porqué razón debe decidir, entonces, sobre la participación de una persona en un delito para ordenar su detención. Acaso no es el ejercicio anterior, la decisión acerca de una hipótesis que le presentó el fiscal, en tanto le aportó unos elementos que vinculan a la persona en la comisión de un delito. ¿No es esto una hipótesis?

Ahora bien, el trámite de la orden de captura no implica seguir con los rigores probatorios del proceso, no obstante, es indudable que el fiscal presenta una hipótesis sostenida en algunos elementos probatorios, a fin de que triunfe y en consecuencia el juez de garantías ordene la respectiva orden. Y esto supondría, entonces, una decisión exenta de dichos rigores de prueba. De esta forma, se está más que nunca sometidos a la libre decisión del juez sin que exista control material de la misma. Por tal motivo, es más acuciante la exigencia de un conocimiento objetivo en la decisión del juez.

Si existe una hipótesis presentada por la fiscalía, cómo debe resolverla el juez de garantías. Ya se vio que no está sujeto a la presentación de pruebas por parte de la persona capturada. Esto genera un espacio grande de decisión en el juez. Quizá, ¿se deba partir desde lo relevante del conocimiento que pueda formarse el juez acerca de la verosimilitud? En el mejor de los casos, el juez tiene un punto de partida incierto en el que los elementos aportados y su propio ejercicio habrían de llevarlo a lo verosímil. Pero, la cuestión no es sencilla como se verá en lo que sigue.

En efecto, la verosimilitud en relación con los motivos razonablemente fundados para emitir una orden que afecte derechos fundamentales, se refiere a lo confiable de la información suministrada, asegurada en el juramento del testigo o informante. Este importante criterio conduce a las notas de legalidad y de exequibilidad de los artículos 221 y 297 de la ley 906 de 2004. Desde luego, el análisis a la manera como el juez de garantías habría de decidir no se realizó por cuanto no era de su competencia salvo las recomendaciones de fallar con base en la racionalidad, la libre apreciación o la sana critica, entre otras. A pesar lo anterior, la verosimilitud no puede quedar entendida como un examen sujeto a la libertad de decisión del juez, debido a que no es una categoría estrictamente jurídica.

Pues, la verosimilitud pertenece a otros campos, en donde tiene su asiento y desde ellos la han proyectado a otros ámbitos para que tenga efectos, como lo es este caso, su uso para motivar una orden de captura o de allanamiento. Por ejemplo, lo verosímil se ha identificado con lo aparente, concretamente, con aquello que tuviera apariencia de verdad. Una apariencia que lograra ser tan fuerte que llevara a la verdad, aunque no fuera cierta. Lo importante es la persuasión o capacidad de ser verdad. 
Es de agregar, que era una categoría más cercana a la literatura que al ámbito judicial. De hecho, esta fue una de las críticas a los sofistas en la época antigua, en que hacían ver cosas verosímiles aun cuando no fueran verdaderas. Este criterio de apariencia fue trasladado en este sentido al desarrollo de los procesos judiciales en la tradición occidental (Herzer \& Naucke, 2008, 39). Si esto es así, ¿significa que la decisión sobre una orden de captura o de allanamiento, se está tomando sobre la apariencia de lo verdadero? Pues es esta la definición de la verosimilitud. Ello implica, entonces, la existencia de falsedades en los elementos probatorios aportados que, no obstante, persuaden hacia una verdad. Conforme a lo dicho, toda decisión judicial debe evitar someterse a estos elementos falsos y ser rigurosa con aquello que le presentan.

Por eso el juramento no puede ser condición para desvirtuar lo falso de la información declarada para soportar una orden de captura. Y si el criterio de lo verosímil se ha mantenido, sin que hasta ahora haya variado su significado, es decir el de apariencia; entonces, debería modularse este concepto en el sentido de concordancia con las libertades y garantías fundamentales, en mejores términos, una noción rigurosa de aquello que se entienda por verosimilitud.

Si se es riguroso, por el bien del derecho a la libertad, se ha de evitar el uso de sinónimos, metonimias y demás juegos del lenguaje cuando nos refiramos a la verosimilitud en cuanto fundamento para decretar una orden de captura. En efecto, ya se vio que lo verosímil es apariencia, no es por tanto la probabilidad, el indicio o la sospecha respecto de la participación en un delito. A no ser que, se asuma que lo probable es igual a lo verosímil, situación que, desde todo punto de vista, no es igual y, por lo mismo, es algo incorrecto.

Además, si se asumiera como válido identificar verosimilitud con probabilidad, se incurre en el error de tratar un sentido de apariencia con verdad. En efecto, la verosimilitud depende de una presentación adecuada, con tendencia a ser verdad, en cambio, la probabilidad requiere de unos pasos lógicos en orden a encontrar como probable la situación que se esté tratando. En definitiva, lo verosímil, depende del discurso, en tanto que la probabilidad exige la rigurosidad del método lógico.
Por consiguiente, el concepto de lo verosímil como fundamento de una orden de captura o de registro y allanamiento, merece ser replanteado, pues, de la declaración de un informante o testigo no se puede colegir su verosimilitud por el solo hecho de estar juramentado y más aún cuando el sistema penal impide la contradicción de este. La crítica al concepto de lo verosímil se desprende de la imposibilidad de confrontar por parte del capturado la declaración que fundamentó su captura.

\section{A MODO DE CONCLUSIÓN: EL CONOCIMIENTO OBJETIVO EN LA DECISIÓN JUDICIAL}

Lo arriba expuesto indica que la tarea del juez en la decisión judicial es tomar los elementos que le son aportados, examinarlos y emitir un nuevo mensaje. Esto significa análisis, reflexión y producción de un nuevo conocimiento llamado orden o fallo judicial. Dicha producción de conocimiento, denominada providencia judicial, está impregnada de un sentido común, -también puede poseer sentido común jurídico-, sobre el cual se construye la respectiva determinación.

En este orden de ideas, las experiencias anteriores, los casos similares, el propio sentido jurídico, creencias y prejuicios, conforman el conjunto de conocimientos que conforman la decisión del juez. Ahora bien, esta acumulación de datos para decidir conlleva a una inercia en las decisiones judiciales, por cuanto ya con base a ellos se anticipa antes del examen del caso, la decisión a tomar. De entrada, ni siquiera la duda es el punto de partida, sino que sería todo ese universo de datos acumulados.

Y esta es la manera, en el ámbito del conocimiento, por la cual se configura la expresión "motivos razonablemente fundados", al momento de expedir una orden de captura y de allanamiento. Esto también significa que el conocimiento es el terreno correcto para abordar y analizar esta expresión. Desde este ámbito se observan las dificultades para formar una decisión. Si esto es así, entonces, la solución también viene por la misma vía, pero en términos de objetividad.

Quiere decir, la decisión judicial está cargada de subjetivismo que afecta el sentido de los "motivos razonablemente fundados", 
en consecuencia, la propuesta es ver hacia un conocimiento objetivo cuya base debe estar en la materialidad. Se busca entonces, un conocimiento que sea producto de la controversia, del debate probatorio, que sea posible refutarlo. Para ello es necesario asumir que se parte de una situación de duda en el plano del conocimiento. Y en una cuestión tan delicada como lo es la afectación de derechos fundamentales, mediante una orden judicial sostenida en los "motivos razonablemente fundados", entonces, la objetividad y el control material constituyen el medio para salir de la duda y deberán prevalecer sobre la subjetividad y el control formal. Una decisión judicial basada en el conocimiento objetivo constituye la racionalidad del fallo proferido y es, en consecuencia, garantía de los derechos y libertades fundamentales.
Desde luego, que este planteamiento puede generar resistencias, pero la apuesta siempre ha de ser que toda decisión judicial esté por encima del universo propio e íntimo del juez y que su raciocinio sea lo más objetivo posible. Por eso, una cuestión como la posibilidad de contrainterrogar al testigo o informante, en los eventos de captura y de allanamiento y registro, genera conocimiento objetivo de la situación, en cuanto surge la posibilidad de examen de todas las circunstancias. Esto constituye un ejemplo claro de alcanzar conocimiento objetivo. Así pues, la discusión acerca de los "motivos razonablemente fundados" es un asunto de la teoría del conocimiento y que puede resultar de gran utilidad para la aplicación de las diligencias de captura y de allanamiento y registro.

\section{BIBLIOGRAFÍA}

- Alexy, R.(1998). Derecho y razón práctica. México: Ediciones Fontamara. Borrero, R, \& Sampedro A. (2010). Sistema acusatorio y jurisprudencia. Bogotá: Editorial Ibáñez. Ferrer, B. (2007).La valoración racional de la prueba. Madrid: Editorial Marcial Pons.

- Feteris, E. (2007). Fundamentos de la Argumentación Jurídica. Bogotá: Universidad Externado de Colombia.

- Herzer, R. \& Naucke, W. (2008). Filosofía del derecho. Buenos Aires: Editorial Astrea.

- Ley 906 de 2004. Bogotá: Senado de la Republica de Colombia. Disponible en http://www.suin-juriscol.gov.co/ viewDocument.asp?ruta=Leyes/1670249

- Ley 1142de 2007. Bogotá: Congreso de la Republica de Colombia. Disponible en http://www.secretarias enado.gov.co/ senado/basedoc/ley_1142_2007.html

- Mill, J. S. (2004). Sobre la libertad". Madrid: Editorial Edaf. Popper, K. (2007). Conocimiento objetivo. Madrid: Editorial Tecnos.

- Sentencia C - 185, de 2008. Bogotá: Corte
Constitucional de la Republica de Colombia, Disponible en https://www.funcionpublica. gov.co/eva/gestornormativo/norma. php?i=36629Sentencia C-366, de 2014. Bogotá: Congreso de la Republica de Colombia, MP. Nilson Pinilla Pinilla. Disponible en http://www.suin-juriscol. gov.co/viewDocument.asp?id=20023002

- Sentencia C - 673, de 2005. Bogotá: Corte Constitucional de la Republica de Colombia. Disponible en http://legal.legis.com.co/ document/Index?obra=jurcol\&document =jurcol_759920420d3bf034e0430a01015 1f034Sentencia C - 226, de 2008. Bogotá: Corte Constitucional de la Republica de Colombia. Disponible en http://legal.legis. com.co/document/Index?obra=jurcol\&doc ument=jurcol_759920424a52f034e0430a0 10151f034

- Zuluaga, T.,J. “De los motivos fundados para la afectación de derechos fundamentales en el proceso penal colombiano". Revista Nuevo Foro Penal, 10 (83), (julio-diciembre, 2014), pp.: 167-209. 